DOI: https://doi.org/10.22206/ceyn.2020.v4i2.pp5-32

\title{
COVID-19 EN MÉXICO: REPERCUSIONES Y RETOS DEL FACTOR HUMANO, FINANCIERO Y FISCAL
}

\author{
Sinuhé Carlos Guardado López ${ }^{\mathrm{a}}$, Jerónimo Martínez Flores ${ }^{\mathrm{b}}$ \\ y Diana Esperanza Tapia Torres ${ }^{c}$
}

Recibido: $1 / 5 / 2020 \bullet$ Aprovado: $2 / 7 / 2020$

Cómo citar: Guardado López, S. C., Martínez Flores, J., \& Tapia Torres, D. E. (2020). COVID-19 en México: repercusiones y retos del factor humano, financiero y fiscal. Ciencia, Economía y Negocios, 4(2), 5-32. Doi: https://doi.org/10.22206/ceyn.2020.v4i2.pp5-32

\begin{abstract}
Resumen
La pandemia del COVID-19 ha generado cambios no solo en las politicas de salud a nivel global, sino que también ha puesto a prueba a los gobiernos de diferentes paises, a sus politicas económicas, monetarias y fiscales, a las empresas y sus finanzas, asi como a sus trabajadores, quienes han sufrido un proceso de adaptación para transitar a lo que se ha denominado la nueva normalidad. Por lo anterior, el presente escrito enfatiza en el impacto que la pandemia del COVID-19 ha tenido en México y sus efectos colaterales en tres rubros medulares para el país y sus organizaciones, como son: el factor humano de las empresas, las finanzas empresariales y el área fiscal. Asimismo, se brinda una critica a las medidas propuestas e implementadas por el Gobierno de México para enfrentar las primeras secuelas de la pandemia en los tres rubros medulares citados. Finalmente, se concluye el manuscrito con una perspectiva hacia el año 2021 de las áreas de comportamiento humano y organizacional (factor humano), financiera-empresarial y fiscal.
\end{abstract}

Palabras clave: comportamiento; trabajador; finanzas; impuestos; México.

Códigos JEL: H2, H32, J2, M1, G3.

\footnotetext{
a Dirección: Universidad Nacional Autónoma de México, Cuautitlán Izcalli, Ciudad México, México. Correo-e: guardadolopez@comunidad.unam.mx

b Dirección: Universidad Nacional Autónoma de México, Cuautitlán Izcalli, Ciudad México, México.Correo-e: jeromar@comunidad.unam.mx

c Dirección: Universidad Nacional Autónoma de México, Cuautitlán Izcalli, Ciudad México, México. Correo-e: tapia.torresLC@hotmail.com
}

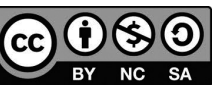

Esta obra está bajo licencia internacional Creative Commons Atribución-NoComercial-CompartirIgual 4.0 Internacional 


\title{
COVID-19 IN MEXICO: REPERCUSSIONS AND CHALLENGES FOR HUMAN CAPITAL AND THE FISCAL AND FINANCIAL SECTORS
}

\section{Sinuhé Carlos Guardado López, Jerónimo Martínez Flores AND Diana Esperanza Tapia Torres}

\author{
Received: 1/5/2020 • Approved: 2/7/2020
}

\begin{abstract}
The named COVID-19 pandemic has brought changes not only in health policies at the global level, it has also tested the governments of different countries, their economic, monetary and taxes policies, companies and their finances, as well as employees, who have undergone a process of adaptation to transit to what has been called the new normality. Therefore, this writing emphasizes the impact that COVID-19 pandemic has had in Mexico and its side effects in three core areas for the country and its organizations, such as: the human factor of companies, business finances and the taxes area. Likewise, it provides a critique of the measures proposed and implemented by the Government of Mexico to face the first repercussions of the pandemic in the three cited core areas. Finally, the manuscript concludes with a perspective towards 2021 of the areas of human and organizational behavior (human factor), financial-business and taxes.
\end{abstract}

Keywords: Behavior; employee; finance; taxes; Mexico.

JEL codes: H2, H32, J2, M1, G3. 


\section{Introducción}

La confirmación por parte de la Organización Mundial de la Salud (OMS) de un nuevo virus llamado Coronavirus de tipo 2, causante del síndrome respiratorio agudo (SRAS-CoV-2), coloquialmente conocido como COVID-19, causó de inmediato un sobresalto entre los especialistas de las Ciencias de la Salud y los académicos e investigadores del área epidemiológica.

El brote de COVID-19 surgido en la ciudad china de Wuhan estremeció a la OMS debido a la facilidad con que se transmitía este nuevo virus; rápidamente se expandió en toda China y llegó a Europa, causando graves estragos y cobrando miles de vidas en Italia, España, Francia y Reino Unido.

En la región de las Américas, Estados Unidos, aun con el siempre radical discurso del polémico Donald Trump, no pudo detener lo que los expertos habían diagnosticado como inevitable: la llegada al continente americano de lo que oficialmente era una pandemia, teniendo como "zona cero" la cosmopolita ciudad de Nueva York.

Consecuentemente, empezaron a surgir casos de COVID-19 en Latinoamérica, destacando por sus cifras países como Brasil, Perú, México y Ecuador, este último transcendiendo mundialmente por las dramáticas imágenes difundidas mediante redes sociales de sus fallecidos en Guayaquil.

Como se aprecia, este nuevo virus ha cambiado la dinámica económica, social, tecnológica, de política pública y sanidad, en diversas regiones de todo el mundo, incluido México. Por tanto, es pertinente llevar a cabo una reflexión y con una mirada crítica determinar las posibles repercusiones que esta pandemia generará en las empresas, específicamente en los rubros del comportamiento del factor humano, los sectores financiero y fiscal.

\section{Factor humano y su comportamiento}

El día 27 de febrero el gobierno mexicano confirmó el primer caso de COVID-19 en territorio nacional. Los tres primeros casos en 
México fueron casos importados de Italia. Tres semanas después, el 18 de marzo, se confirmó el primer fallecimiento de un masculino de 41 años por este nuevo virus. Mientras que las actividades educativas se suspendían a partir del 20 de marzo en todos los niveles educativos.

No obstante, la atención del país se centraba en el momento álgido de la pandemia, cuando esta se declarara en fase 3 , ya que tal declaratoria no implicaba solo un exhorto a parar actividades empresariales y laborales no esenciales, esa declaratoria era una llamada ineludible e impostergable a detener la actividad económica.

El plazo se cumplió y el martes 21 de abril de 2020, en la conferencia matutina del presidente López Obrador, el Subsecretario de Prevención y Promoción de la Salud, el Dr. Hugo López-Gatell, emitió de forma colegiada con el Consejo de Salubridad la declaratoria de fase 3 de la pandemia de COVID-19 en México. Por tanto, la mayoría de las empresas se vieron obligadas a detener su actividad económica, incluidas algunas dependencias del sector público, al no desarrollar estas una actividad esencial.

Este escenario puso a prueba a numerosas organizaciones, las cuales tuvieron que migrar su modo de trabajo, de ser presencial a trabajar en línea o de forma semipresencial. Las organizaciones asumieron el reto emergente de las plataformas de trabajo en línea. Por su parte, los trabajadores tuvieron que aplicar, o bien, desarrollar las competencias tecnológicas necesarias para poder efectuar el llamado home-office.

$\mathrm{Al}$ respecto, la Confederación Nacional de Cámaras de Comercio (CONCAMIN) señaló que para finales de abril el $82 \%$ de las empresas especializadas en comercio, servicios o turismo del país se mantenían en cierre temporal, cierre permanente o disminución de horario de operaciones (Alfaro, 2020). Mientras que el Consejo Nacional de la Industria Maquiladora y Manufacturera de Exportación (INDEX) informó que en mayo, el $45 \%$ de las empresas del sector permanecían cerradas en México ante el confinamiento por el coronavirus Covid-19 (Morales, 2020). Por su parte, el presidente de la Cámara de Comercio, Servicios y Turismo de la Ciudad de México (Canaco-CDMX), Nathan Poplawsky, estimó que en la capital han cerrado más de 270 mil empresas debido a la contingencia sanitaria por coronavirus (Marco, 2020). 
La numeralia presentada por parte de la Secretaría del Trabajo y Prevención Social (STPS) al 19 de mayo del presente año señalaba que el $94 \%$ de las empresas inspeccionadas cumplían las medidas sanitarias ante el COVID-19, mientras que el $6 \%$ se negó al cierre. Respecto al porcentaje dentro de las industrias que se negaron al cierre, principalmente están las tiendas departamentales, con un $26 \%$, comercio de productos no esenciales, con el $26 \%$, y la venta, reparación, mantenimiento y distribución de vehículos para uso particular, con un $20 \%$. Lamentablemente, el $42 \%$ de las empresas que se negaron a cerrar se encuentran en los municipios más afectados por la pandemia. Por lo expuesto, la titular de la STPS hizo un llamado a los empresarios para que no relajen las medidas sanitarias y cumplan con la normatividad ante el COVID-19 para cuidar a sus trabajadores y continuar con la Jornada Nacional de Sana Distancia (STPS, 2020a).

No obstante, hubo empresas que no desarrollaban actividades esenciales y siguieron operando, por ejemplo, empresas como Elektra de Grupo Salinas tramitaron amparos para poder continuar operando con la justificación de que desarrollaban una "actividad esencial". Otras empresas como Grupo Nach y Staff E\&I, que proveían servicios de call center al referido Grupo Salinas, desobedecieron el llamado de la STPS ya que, aun con los sellos de suspensión de actividades colocados por el Instituto de Verificación Administrativa del Gobierno de la Ciudad de México, violaron la suspensión e ingresaron a sus trabajadores por un acceso alterno que se encontraba en un edificio contiguo. Esto fue documentado en redes sociales por medio de un video que subió uno de los empleados de la empresa.

Es menester señalar que el Gobierno de México planteó e instrumentó la llamada Guía de acción para los centros de trabajo ante el Covid-19, la cual armonizó con la Jornada Nacional de Sana Distancia. Entre los puntos que se pueden destacar de esta guía, relacionados con el desempeño de los empleados, se destacan:

1. Designar al personal responsable de mantener informado a todos los colaboradores del centro de trabajo respecto a las indicaciones de la autoridad sanitaria. 
2. Identificar si el centro de trabajo puede continuar laborando durante la Jornada Nacional de Sana Distancia.

3. Identificar dentro del centro de trabajo al personal de mayor riesgo que, por su condición, deba aplicar estrictamente el resguardo domiciliario corresponsable.

4. Flexibilizar el trabajo, permitir la reorganización de los turnos y el escalonamiento de las jornadas laborales, así como el uso de las tecnologías para minimizar el contacto directo, incluyendo el teletrabajo.

5. Identificar las funciones que por su grado de exposición o atención al público sean más riesgosas de infección ante el COVID19.

6. Identificar las actividades esenciales para mantener la actividad del centro de trabajo.

7. Suspensión de actividades que involucren la concentración física superior a 50 personas en espacios cerrados o que impliquen actividades en las que no se pueda implementar una distancia de 1.5 a 2.0 metros entre cada puesto de trabajo o persona trabajadora.

8. Evitar el retorno de trabajadores enfermos sin contar con la evaluación médica pertinente.

9. Fomentar y brindar confianza para que los/as trabajadores/as se retiren ante la presencia de síntomas de la enfermedad, a través de la simplificación de trámites de incapacidad y la eliminación de descuentos por ausencia.

Sin embargo, en materia de salud mental concretamente, la STPS no hizo ningún pronunciamiento en esta Guía de acción para los centros de trabajo ante el Covid-19, lo que permite reflexionar y cuestionarse respecto a la dimensión que se le otorga a la salud mental del trabajador; parece que tal guía se limita a la salud física del trabajador, así como a la relativa productividad que deben mantener algunas 
empresas consideradas como esenciales, dejando al trabajador a la deriva en su plano psicológico.

En contraste, el Estado, en sus tres órdenes de gobierno, por medio del sector salud y otras instituciones educativas y de investigación, como es la máxima casa de estudios: UNAM, dispusieron de todos los recursos humanos y tecnológicos posibles para afrontar las emociones que generó el confinamiento en una importante cantidad de personas y, por supuesto, de empleados, como consecuencia del aislamiento voluntario, destacan emociones como: miedo, tristeza, ira, frustración y soledad. De igual modo, este aislamiento voluntario generó o ha potencializado problemas de origen neurofisiológico, por ejemplo: ansiedad, depresión y trastornos del sueño, como el insomnio.

$\mathrm{Al}$ respecto, la Organización Mundial de la Salud (2016) expresa que la amenaza a la seguridad y al funcionamiento normal del individuo y su comunidad se expresa, en más del $80 \%$ de las personas, con un incremento de síntomas que podrían afectar su salud mental, como la angustia, el miedo e incluso el pánico y el terror. Es normal experimentar ansiedad, tensión, inseguridad y vigilancia obsesiva de los síntomas de la enfermedad. Mientras que el enojo, la irritabilidad y la indignación son emociones que derivan de una percepción disímil del riesgo. Otras manifestaciones comportamentales que se experimentan son sentimientos de abandono, vulnerabilidad, liderazgos espontáneos (positivos o negativos), duelos, estrés agudo, descompensación de trastornos psíquicos preexistentes, trastornos somáticos de origen psíquico, conductas agresivas y de protesta contra autoridades e instituciones con actos de rebeldía y/o delincuenciales, violencia intrafamiliar, etc.

El factor humano que labora de forma ininterrumpida en el sector salud, sea público o privado, puede llegar a presentar en el corto plazo crisis emocionales, reacción aguda al estrés, desgaste profesional o burnout, abuso de alcohol, de tabaco y de sustancias psicoactivas; así como precipitación o exacerbación de trastornos de ansiedad generalizada y síntomas depresivos. A mediano y largo plazo, se suman el trastorno por estrés postraumático, la dependencia a sustancias, a alcohol y a tabaco; la fatiga por compasión, el duelo y, en todo momento, el riesgo suicida (Secretaría de Salud, 2020). 
En las crisis epidemiológicas se incrementa el riesgo de problemas de salud mental a causa de las medidas de aislamiento, restricción de movilidad y disminución en el contacto físico directo. Las personas que pasan tiempo en aislamiento pueden mostrar síntomas de depresión grave y síntomas relacionados con el estrés postraumático hasta tres ańos después (Brooks et al., 2020).

Por su parte, las Secretarías de Gobierno mencionadas (Secretaría de Salud y la Secretaría del Trabajo y Previsión Social) no especifican líneas de acción a favor de la salud mental de los trabajadores o empleados, solo abordan de manera global a los adultos por medio del documento titulado Lineamientos de respuesta y de acción en salud mental y adicciones para el apoyo psicosocial durante la pandemia por COVID-19 en México.

Los lineamientos referidos no especifican medidas aplicables al centro de trabajo ni que sean para empleados, solo generalizan a la población adulta. Algunos lineamientos que se destacan son:

- Identificar los servicios de atención a la salud mental y las adicciones en la comunidad (Centro Integral de Salud Mental, Centro de Atención Primaria a las Adicciones, Centro Comunitario de Salud Mental y Hospital Psiquiátrico).

- Brindar apoyo emocional e intervención en crisis a través de los centros de soporte telefónico, en línea o medios digitales, incluidas técnicas para el manejo del estrés.

- Alentar a que las personas mantengan la comunicación con personas de su entorno, especialmente aquellos de sus círculos de amigos y familiares, a través de internet $\mathrm{u}$ otros medios.

- Asegurar la atención psiquiátrica y psicológica a las personas con trastornos mentales definidos en unidades de salud mental y de adicciones, así como en unidades hospitalarias.

El contexto señalado en materia de salud mental laboral no minimiza los estragos laborales que dejó esta primera oleada de COVID-19 en México, como la pérdida de 130, 593 puestos de trabajo en marzo 
del presente año; para el 6 de abril de 2020 se habían perdido 346, 878 empleos formales (EFE, 2020; Secretaría del Trabajo y Previsión Social, 2020c). Por su parte, el presidente López Obrador estimó que se perderán cerca de 1 millón de empleos, como consecuencia del COVID-19 en México, mientras que en Estados Unidos se estima que se alcancen los 20 millones de empleos perdidos (El Financiero, 2020).

El golpe económico del COVID-19 también implica reducciones de salario, falta de pago de la renta (arrendamiento) de las viviendas, locales, consultorios y oficinas, así como la bancarrota de numerosas empresas, sobre todo MiPYMES, que son más vulnerables económicamente y cuentan con una plantilla laboral más susceptible de ser recortada. La importancia de este sector organizacional se respalda en cifras del Instituto Nacional de Estadística, Geografía e Informática (INEGI), que señala que las microempresas (de 1 a 10 empleados) representan el $95.4 \%$ del total de las empresas del país, mientras que las pequeńas empresas conforman un $3.6 \%$ y las medianas un $0.8 \%$. Su contribución total al Producto Interno Bruto (PIB) ronda el $52 \%$ y generan el $72 \%$ del empleo formal (INEGI, 2019a).

Los eventos de índole económica señalados ineludiblemente contribuyeron, mas no fueron determinantes ni predisponentes, a su vez, en los documentados intentos de suicidio o en la consumación de estos dentro de los centros hospitalarios. Con relación a lo enunciado, Brooks et al. (2020) señalan que la separación de los seres queridos, la pérdida de la libertad, la incertidumbre sobre el estado de la enfermedad y el aburrimiento pueden causar efectos psicológicos adversos, conductas de evitación, de confusión, de frustración y de enojo; incluidos los síntomas de estrés postraumático que podrían escalar hasta el suicidio.

En otros casos, los familiares de los pacientes o estos mismos agredieron al personal de salud, incurriendo en actos de allanamiento y de sustracción del enfermo, o bien, participaron de forma activa en su retiro voluntario, aun sin la alta médica correspondiente. En este tenor, como ejemplo, se documentaron los casos de hospitales en Hidalgo (Tepeji del Río) y el Estado de México (Las Américas, Ecatepec).

Los problemas de salud mental y la incidencia o exacerbación de trastornos mentales en forma aguda o de crisis dependerá de la 
magnitud de la pandemia, del grado de vulnerabilidad de la población, de la respuesta de los servicios de salud y de las características individuales de afrontamiento y resiliencia de las personas afectadas por la emergencia; además, el temor de contagiar o ser contagiado agrava la situación (Secretaría de Salud, 2020).

Por tanto, cuando las empresas regresen a la llamada nueva normalidad, la cual supone nuevas condiciones de adaptación y colaboración en materia sanitaria, psicológica y grupal en las empresas, será frecuente encontrar:

(...) un aumento de síntomas depresivos, de manifestaciones de estrés postraumático, de abuso en el consumo de alcohol y otras sustancias psicotrópicas y de manifestaciones somáticas del estrés, como dolor de cabeza, problemas gastrointestinales, entre otros. También es normal encontrar tristeza ante las pérdidas; y será necesario considerar que el duelo es un proceso normal que no debe apresurarse ni considerarse como una enfermedad (Secretaría de Salud, 2020, p. 15).

Lo enunciado evidencia que los esfuerzos en materia de salud mental en estos casos siempre serán insuficientes para cualquier sistema de salud del mundo. Por tanto, las empresas en México y en Latinoamérica tienen un importante e inaplazable reto, que implica no solo reactivarse económicamente mediante el trabajo desempenado por sus trabajadores; primeramente, es ofrecer las condiciones sanitarias necesarias previas al arribo de sus trabajadores, para dar paso al establecimiento de un clima organizacional adecuado y configurar un ambiente psicológico que permita al trabajador ser productivo, incluso después de un evento complejo en materia de salud mental y económica de alcance global.

\section{Aspecto financiero}

La pandemia sanitaria del COVID-19 ha impactado a la economía, afectando intensamente a todo tipo de empresas. Con el paro temporal de algunas actividades y algunos negocios se genera 
una desaceleración económica y las consecuencias de este suceso son peores para la economía global que las derivadas de la crisis financiera en el período 2007-2008.

El primer país en sufrir el impacto del COVID-19 fue China, la segunda economía más grande del mundo. El drástico bloqueo implicó que varias empresas manufactureras y negocios minoristas importantes cerraran o disminuyeran sus actividades, lo cual generó un frenado para la economía china.

En términos de consumo, en comparación con el año 2019, las ventas minoristas en enero y febrero cayeron un $20.5 \%$ (Weiland \& Kynge, 2020). Afortunadamente, China ha podido contener la propagación del virus, por lo que los fabricantes chinos han retomado en gran parte su ritmo de producción. El escenario económico que se está experimentando, así como todos los desafíos que se tienen que superar de manera colectiva difícilmente se pueden comparar con otros contextos que hayan surgido durante casi un siglo.

Ante el aumento de casos confirmados de COVID-19 en México, la moneda mexicana se depreció más de un $30 \%$ a finales de febrero, el dólar cerró en 19.64 pesos y, específicamente, el 23 de marzo cerró en 25.68 pesos. Sin embargo, el choque en la producción apenas comienza (García \& González, 2020). Mientras más personas dejen de laborar, tanto en México como en Estados Unidos, la presión sobre el tipo de cambio aumentará debido a seis factores:

I) El colapso del sector turístico representó el $8.7 \%$ del PIB en México, en 2019. Las restricciones de vuelos, el cierre de hoteles, playas y atracciones turísticas harán que el sector sea una de los más afectados por un tiempo indefinido. La entrada de divisas internacionales por actividades turísticas fue de un $1.9 \%$ del PIB en 2019. Además, el sector emplea al $6 \%$ del sector formal remunerado del país.

II) La disminución esperada en las remesas debido a la contracción de la actividad económica en Estados Unidos. Goldman Sachs espera una reducción del PIB de EE. UU. de un $3.8 \%$ en 2020 (y del $24 \%$ anualizado en el segundo trimestre). Por otro lado, las 
remesas representaron el $2.9 \%$ del PIB durante 2019. Esto representa una disminución en el ingreso disponible de hogares vulnerables, además de una menor oferta de dólares en México.

III) La disminución en las exportaciones debido a la reducción de la demanda por bienes mexicanos en el extranjero. La actividad manufacturera representó el $15.9 \%$ del PIB en 2019 y las exportaciones manufactureras representaron el $89 \%$ de las exportaciones totales. El cierre de plantas en el sector automotriz y otros sectores tendrán repercusiones fuertes sobre la actividad económica, así como en el mercado laboral.

IV)El colapso en el precio del petróleo. La Mezcla Mexicana de Exportación cayó a un mínimo histórico de 14.54 dólares por barril, lo cual implica una menor cantidad de dólares entrando a la economía mexicana. La disminución de los ingresos de Pemex representa un reto adicional para el sector público, debido a la posición financiera deficitaria de la empresa. Está por verse la reacción de las agencias calificadoras con respecto a la calificación de su deuda y su repercusión sobre el valor del peso.

V) La apreciación del dólar vis-à-vis otras monedas debido al efecto "flight to safety" en contextos de incertidumbre internacional, en el que inversionistas internacionales buscan bonos seguros.

VI) El papel de las expectativas: si los mercados internacionales anticipan que la demanda por consumo o la cadena de suministro en México va a estar comprometida de tal manera que imposibilite una recuperación en forma después de la crisis, los inversionistas perderán la confianza en el peso, incluso antes de que ese escenario se materialice.

Los factores citados reducen la cantidad de dólares que entran a la economía mexicana. Mientras que las grandes empresas implementaron planes para operar, sobre todo en áreas corporativas, hasta con un $50 \%$ menos de empleados en los centros de trabajo, las fábricas u oficinas, con el fin de evitar la propagación del coronavirus. 
Por tanto, el tiempo es un factor elemental para cientos de negocios establecidos en el país, pues según expertos la mayoría de ellos necesita más de cinco años en el mercado para poder resistir el escenario que actualmente se vive en México a causa del coronavirus. El paralizar la ciudad y cerrar decenas de locales para evitar todavía más la propagación del COVID-19 afecta inconmensurablemente a cientos de pequeños y medianos empresarios.

Las PYMES (pequeñas y medianas empresas) como papelerías, hoteles, tiendas, fondas, cafeterías, entre otras, viven "en carne propia" el daño que ha dejado la emergencia sanitaria en el país. Marco González, socio de People Advisory Services (PAS) de la prestigiada firma EY, destacó que las PYMES más jóvenes tienen menor capacidad de reinventarse ante esta contingencia:

Si las PYMES tienen más de cinco años operando, posiblemente tengan la capacidad de sobrellevar la crisis. Cuando estas tienen menos de cinco ańos de apertura están en etapa de crecimiento por lo que su panorama no es claro y es más difícil que lo logre (Gascón, 2020, p. 1).

Los censos económicos de 2019 revelan que en el país hay 1.8 millones de empresas con una antigüedad de menos de cinco años de subsistencia. Mientras que aquellas empresas de mayor tiempo laborando, es decir, entre seis y 10 años de antigüedad, así como las de más de 10 años, suman 2.9 millones (INEGI, 2019b).

Héctor Magaña, coordinador de Análisis e Investigación del Centro de Investigación en Economía y Negocios del Tec de Monterrey, advirtió que para aquellos que tengan al menos dos años trabajando lo más difícil será mantenerse económicamente, ya que tienen que invertir, pagar a los trabajadores, entre otras cosas.

Para las de reciente creación, aquellas que tengan unos dos años en el mercado, va a ser complicado porque les va a afectar en su capital de trabajo, es decir, van a tener muy poco dinero para adquirir los insumos de los proveedores, para poder pagarles a 
sus empleados, esto va a traducirse en que tendrán que reducir su personal y en el peor de los casos, en cerrar.

El tiempo que puedan resistir estas empresas también dependerá de qué tanto puedan apoyarse en bancos o instituciones financieras, las cuales pueden ser flexibles en cuanto a los pagos que deben realizar esas empresas o en el otorgamiento de algún crédito para solventar estos problemas (Reforma, 2020).

Como resultado de la contingencia por el COVID-19, se anticipa una crisis sin precedentes, donde las empresas más vulnerables serán las micro, pequeńas y medianas (MIPYMES), advirtió Enoch Castellanos, presidente de la Cámara Nacional de la Industria de Transformación (CANACINTRA), al afirmar que no hay empresa que pueda aguantar más de mes y medio si sus ventas caen de repente.

En la siguiente tabla se observa la cantidad de empleos ubicados por el tipo de unidad económica, en donde se puede apreciar que la gran mayoría de los empleos son generados por las unidades de MiPYMES, siendo responsables de 35.9 millones de empleos que están en riesgo de desaparecer ante la pandemia del coronavirus.

Tabla 1. Población ocupada por ámbito y tamaño de la unidad económica

\begin{tabular}{|l|c|}
\hline \multicolumn{1}{|c|}{ Ámbito } & Número de personas \\
\hline Agropecuario & $\mathbf{6 , 9 0 9 , 8 1 9}$ \\
\hline Micronegocios & $\mathbf{2 2 , 4 1 5 , 4 2 3}$ \\
\hline Pequeños establecimientos & $\mathbf{8 , 2 1 7 , 4 8 9}$ \\
\hline Medianos establecimientos & $\mathbf{5 , 6 8 9 , 4 6 9}$ \\
\hline Grandes establecimientos & $5,049,414$ \\
\hline Gobierno & $2,401,147$ \\
\hline Otros & $2,708,220$ \\
\hline No especificado & $2,292,469$ \\
\hline TOTAL & $55,683,450$ \\
\hline
\end{tabular}

Fuente: STPS, Encuesta Nacional de Ocupación y Empleo, 2019. 
Frente al escenario descrito, el presidente López Obrador, a partir del lunes 27 de abril, hizo entrega de créditos directos para las PYMES con el propósito de reactivar la economía durante la contingencia por el COVID-19. Se acordó dar un millón de créditos para la economía formal e informal, para pequeñas empresas familiares; 25 mil millones de pesos, para un millón de beneficiarios, dando prioridad a las empresas que tiene trabajadores dados de alta ante el Instituto Mexicano del Seguro Social (IMSS) y que a pesar de la crisis económica no fueron despedidos. Conforme a datos de la Secretaría de Economía del Gobierno de México, fueron contabilizadas 645, 102 PYMES, de las cuales más de 500, 660 poseen de uno a cinco trabajadores.

\section{Área fiscal}

La pandemia del COVID-19 ha causado importantes alteraciones en aspectos económicos, administrativos, sociales, así como fiscales, los cuales han comprendido el cierre de fronteras y la importante pérdida de impuestos que el Estado había presupuestado como ingresos del ejercicio fiscal 2020. Por lo anterior, la respuesta fiscal del gobierno de México será limitada. Sin embargo, el Estado se ha pronunciado durante esta contingencia sanitaria para brindar apoyo a los contribuyentes, quienes son parte fundamental en la economía de México, y para que el Gobierno Federal siga obteniendo recursos económicos que le permitan sostenerse.

Es importante señalar que, a pesar del panorama adverso del COVID-19, durante el primer trimestre el Servicio de Administración Tributaria (SAT) informó cifras preliminares de 2020, en las que mediante comparativa rebasaba con un $13.4 \%$, poco más de 1 billón 3 mil millones de pesos mmdp al primer trimestre de 2019. Los impuestos con mayor recaudación fueron Impuesto sobre la Renta (ISR), Impuesto al Valor Agregado (IVA) y el Impuesto Especial sobre Producción y Servicios (IEPS), con incrementos del 16.3\%, $12.6 \%$, $5.0 \%$, respectivamente. Asimismo, los accesorios aumentaron en un $76 \%$ (Servicio de Administración Tributaria, 2020a).

Asimismo, el presidente Andrés Manuel López Obrador señaló que incluso con la contingencia el Gobierno Federal seguirá implementando medidas para la recaudación de los impuestos que le 
corresponde pagar a cada contribuyente; adicional a esto, se seguirá eliminando el trato preferencial que tuvieron ciertos contribuyentes en sexenios anteriores; no obstante, el pago que les corresponderá siempre será de forma equitativa y proporcional.

De igual forma, uno de los aspectos relevantes que las empresas en México deben considerar es la falta de liquidez, la cual podría extender la no deducibilidad por la reducida utilidad causada durante el período en que se determinó la Jornada Nacional de Sana Distancia.

Por su parte, José Ángel Gurría, secretario General de la Organización para la Cooperación y el Desarrollo Económico (OCDE), señaló que México necesita utilizar todos los estímulos monetarios y fiscales posibles y, sobre todo, dar oxígeno a pequeñas y medianas empresas (PYMES).

Por otro lado, el SAT ha tenido que implementar ciertas modificaciones de forma, como los plazos de recaudación, comunicando el 22 de abril de 2020 una ampliación del plazo para la presentación de la declaración anual de personas físicas con fecha límite del 30 de junio de 2020, teniendo como objetivo principal la realización de trámites necesarios para llevar a cabo la declaración anual desde internet. Lo anterior, debido a la demanda que se vivió para generar y actualizar la contraseña de los contribuyentes.

De este modo, el Estado facilitaría y mejoraría, en términos de monto económico, la recaudación; además, el contribuyente gozaría de dos meses adicionales para realizar sus trámites y cumplir con la obligación de contribuir al gasto público, establecida en el artículo 31 de la CPEUM: "Art. 31.- Son obligaciones de los mexicanos: (...) IV. Contribuir para los gastos públicos, así de la Federación como del Estado y Municipio en que residan, de manera proporcional y equitativa que dispongan las leyes." (CPEUM, 1917).

El objetivo de ampliar el plazo para la presentación de las declaraciones anuales de las personas físicas, a interpretación de los profesionales en la materia, tiene un doble interés por parte del SAT, ya que las personas físicas son las que en su mayoría determinan saldos a favor de ISR anualmente, por sus deducciones personales y retenciones, solicitándolos en devolución. 
Al respecto, la SHCP sigue analizando los incentivos fiscales que se pueden emitir, de modo que se puedan aplicar las medidas concernientes para beneficiar a diversos sectores, sobre todo a los más afectados, como consecuencia de la reducción y/o suspensión de actividades económicas. Es menester señalar que el Gobierno federal no permitirá malas prácticas en materia fiscal pese a la contingencia, ya que el presidente Andrés Manuel López Obrador señaló que la recaudación del primer cuatrimestre debía enfrentarse por los contribuyentes aun con la crisis de la pandemia causada por el COVID-19 y claramente tal objetivo se alcanzó por la finalización de los privilegios fiscales y la condonación de impuestos.

En este sentido, el 23 de junio de 2020, en su conferencia de prensa diaria, el presidente López Obrador informó sobre las acciones que se llevarán a cabo en contra de las Empresas que Deducen Operaciones Simuladas (EDOS) y Empresas que Facturan Operaciones Simuladas (EFOS), ya que estas entidades se encargan de defraudar a la SHCP emitiendo y comprando facturas de forma que se puedan simular operaciones que evitan contribuir al gasto público de forma equitativa y proporcional, con relación al nivel de ingresos del contribuyente.

La estrategia del Gobierno de México busca un balance entre la necesidad de apoyar e impulsar la economía y la disciplina fiscal. Se reconoce la importancia de contar con un espacio fiscal como el considerado en el Decreto de Presupuesto de Egresos de la Federación, así como de asegurar el despliegue del gasto y la inversión que se necesitan en la coyuntura, con la finalidad de que las finanzas públicas no contribuyan a agravar la situación macroeconómica.

Para este fin se buscará mejorar la eficiencia recaudatoria y generar ahorros presupuestales, especialmente en el gasto corriente, para financiar los programas prioritarios del Gobierno Federal, así como para atender las eventualidades de emergencia de salud y económicas que se presenten como resultado del brote epidemiológico. Adicionalmente se planea privilegiar como fuente de financiamiento 
el uso de activos financieros del sector público con la finalidad de minimizar el uso de un mayor endeudamiento (SAT, 2020b).

En esta línea, el martes 23 de junio de 2020, el Gobierno federal informó y presentó ante la Fiscalía General de la República un primer paquete de denuncias en contra de 43 empresas factureras, en las cuales participaron 8,212 empresas y personas, con un total de 93,000 mdp en operaciones simuladas, las cuales causaron 24,583 mdp de ISR y 11,296 mdp de IVA. Asimismo, empresas que pagaron nómina y no pagaron las retenciones de ISR al SAT alcanzaron un monto de 19,146 mdp. Por lo anterior, del año 2010 al año 2019 el SAT dejó de percibir un total de 55,125 mdp.

La jefa del SAT, Raquel Buenrostro, argumentó que los impuestos que se causaron bajo el rubro de ISR e IVA son impuestos que difícilmente se podrán recuperar; sin embargo, para las retenciones de ISR se tomarán acciones como el envío de cartas a todos los contribuyentes por medio del buzón tributario con la invitación a que se regularicen y comprueben sus operaciones. De lo contrario, se le dará aviso a la Procuraduría Fiscal y se emplearán medidas más drásticas, atacando al constituidor de las empresas y al comprador de las facturas.

Por su parte, el Procurador Fiscal de la Federación, Carlos Romero Aranda, informó que se dará un plazo de tres meses para que los contribuyentes de buena fe manifiesten que sus operaciones realizadas y relacionadas con factureras fueron por desconocimiento; de lo contrario, la Procuraduría Fiscal presentará la querella correspondiente contra quien compró la factura y el que la vendió. Por lo anterior, es evidente que el actual Gobierno federal ha emprendido una transformación en la praxis fiscal mediante varias acciones que se traducen en una reorientación de la cultura tributaria.

\section{Conclusión}

En el área del factor humano, el verdadero desafío para las empresas es el regreso escalonado a los centros de trabajo con las medidas de sanidad adecuadas; cuidar no solo de la salud física de los trabajadores, es fundamental identificar el estado de salud mental que guardan los 
trabajadores para quienes el período de confinamiento pudo haber dejado secuelas emocionales: algunos pudieron perder un ser cercano; otros pudieron estar enfermos o un familiar de ellos, inclusive pudieron estar internados; o bien, pudieron desarrollar un trastorno que incluso pueda derivar en el plano psiquiátrico.

Este desafío que se plantea versa en la oportuna, científica y correcta detección del estado de salud mental. Del mismo modo, una propuesta es clasificar al personal de las empresas en México en cuatro grupos: empleados sin COVID-19 durante la Jornada Nacional de Sana Distancia (JNSD); empleados que enfermaron por COVID-19 durante la JNSD; empleados con un familiar, amigo o compañero de trabajo remitido a un centro hospitalario por COVID-19 durante la JNSD; y empleados con un familiar, amigo o compañero de trabajo fallecido por COVID-19 durante la JNSD.

Lo antes planteado se propone con fines de evaluación y monitoreo psicológico quincenal o mensual durante los próximos nueve a doce meses para que la empresa, mediante su área de recursos humanos o el responsable de tal función, coordine los esfuerzos y canalice, o bien, subcontrate de manera temporal los servicios de una clínica o de personal especializado en psicología clínica. Asimismo, se debe vislumbrar la posibilidad de la atención psiquiátrica con algunos empleados, pero solo mediante la recomendación de personal especializado en el ámbito clínico, no organizacional, ni de un psicólogo general.

Es necesario que las empresas se comprometan, pero más que actúen, lo que resta del año y durante el año 2021, en favor de las medidas sanitarias en sus respectivos centros de trabajo y que diagnostiquen, fomenten y traten el aspecto emocional de los empleados, llevando a cabo intervenciones científicas y detectando diversos factores de riesgo psicosociales que puedan existir, o bien, predisponer en su salud mental al trabajador. La implementación de psicoeducación es fundamental ante las pérdidas y el duelo para el desarrollo de la resiliencia. La psicoeducación contemplaría, por ejemplo: técnicas para el control de la ansiedad y depresión; técnicas de relajación y meditación; orientación sobre temas como conducta suicida, trastorno por estrés postraumático, ataques de pánico, etc. 
Asimismo, se necesita la creación de espacios, grupos o talleres dentro de las empresas para promover el bienestar mental del factor humano. Todo esto coordinado por un profesional de la salud mental clínica, para lograr la formación, el desarrollo y la consolidación de grupos de encuentro (Rogers, 2012).

El regreso a lo que se ha llamado la nueva normalidad supone que las empresas cumplan con una apreciación integral del ser humano, algo a lo que no estaban acostumbrados o nunca hicieron. Ahora será esencial cuestionar antecedentes de salud mental, trastornos mentales y consumo de sustancias; así como conocer y familiarizarse con esquemas actuales de tratamientos farmacológicos. Aun en ausencia de antecedentes personales patológicos de salud mental, los trabajadores pueden experimentar malestar psicológico relacionado con la epidemia y es probable que estas personas requieran apoyo adicional (Secretaría de Salud, 2020).

Si las empresas son omisas en la procuración de la salud mental en el período post-pandemia dejaría en una posición mediática peor al ya desgastado socialmente gran sector empresarial (no a las MiPYMES), frente a la opinión pública. Como prueba de lo anterior, están los ejemplos puntuales de algunas empresas, centros de distribución (Cedis) y maquiladoras del norte de México, que incluso con la expresa indicación del gobierno de suspender actividades en el período crítico de la pandemia (fase 3), no acataron las indicaciones e incluso algunas empresas buscaron amparos para no dejar de trabajar, exponiendo a sus trabajadores al contagio del COVID-19.

El contexto señalado permite ampliamente justificar el diagnóstico y la detección de los factores psicosociales que hayan detonado algún trastorno en alguno de los trabajadores. Asimismo, el trabajo coordinado con algunos psicólogos clínicos mediante diversas técnicas terapéuticas que favorezcan la detección, pero a la vez que promuevan la apertura emocional, la autenticidad y la consecuente aceptación de un área de oportunidad psicosocial con el equipo de trabajo es primordial porque aumentaría la cohesión del grupo y coadyuvaría en el cumplimiento de sus metas, además impulsaría que entre los integrantes se adopten actitudes de empatía, cooperación y fraternidad. 
Es primordial no perder de vista que en algunos casos muy puntuales, como se refirió, se puede requerir de un apoyo psiquiátrico de forma paralela para lograr un equilibrio emocional del trabajador con mejores resultados en su salud mental, reflejándose en su productividad laboral y calidad de vida. Es menester señalar que, en ocasiones, los trabajadores previo al confinamiento pudieron requerir una atención psicológica o psiquiátrica; sin embargo, las pruebas psicométricas y psicológicas que se aplican en los procesos de selección de personal se caracterizan por ser someras o simplemente hay rasgos de la personalidad que no miden. Lo anterior refuerza la necesaria migración a un enfoque de Neuroselección del talento humano mediante la aplicación de la Neuropsicología Organizacional (Guardado, 2020; 2019; 2018).

En cuanto al aspecto financiero, el escenario más optimista para los trabajadores mexicanos sería aquel en el cual se lograran rescatar la totalidad de los empleos; sin embargo, esto ya es imposible debido a la contracción estimada de más del $6 \%$ del PIB y la posible recesión mundial que se avecina, entre otros factores que golpearán la economía mexicana.

Por tanto, el mejor escenario que se podría plantear para la población trabajadora sería aquel en donde no se perdieran más de 2.7 millones de empleos y que la cifra de total de mexicanos sin ocupación no rebasara los 4.8 millones de personas para ubicar la tasa de desempleo en un $7.7 \%$.

Sin embargo, siendo lo más realistas posibles, el escenario más probable para los trabajadores mexicanos se orientará en rescatar la mayoría de los empleos en actividades primarias, aunque se sufran cuantiosas pérdidas de puestos del sector terciario a causa de los factores que golpearán la economía mexicana. Este escenario estima que se perderían aproximadamente 3.2 millones de empleos y que la cifra total de mexicanos sin ocupación no rebasará los 5.2 millones de personas, para ubicar la tasa de desempleo en un $9.3 \%$.

El peor escenario que se podría vislumbrar para la población trabajadora podría ser aquel en donde se perdieran más de 3.8 millones de empleos y en el que la cifra de total de mexicanos sin ocupación rebasara los 6 millones de personas, para ubicar la tasa de desempleo en un $10.36 \%$. 
Sin embargo, para el año 2021 se espera una recuperación por los efectos de la pandemia de COVID-19. Se estima que el crecimiento económico mejore con respecto al año 2020, ubicándose entre el 1.5 y $3.5 \%$, rango basado en la mejoría en la actividad económica que se espera desde el tercer y cuarto trimestre de este ańo, una vez que concluya la contingencia sanitaria.

La cantidad de empleos que se pierdan dependerá de los estímulos que se extiendan a la economía y al trabajo, por lo que los gobiernos en sus tres órdenes tendrán que impulsar políticas fiscales orientadas a los sectores que mayor riesgo tienen de pérdida de empleos. En México, que sufrirá los mayores estragos, será el sector terciario; seguido de las actividades relacionadas con las manufacturas, el comercio minorista y mayorista, el turismo y las empresas del ramo de los alimentos, teniendo en cuenta que en México existe un "mundo laboral" que opera en la informalidad y que requerirá ser tomado en cuenta por lo que aporta de manera económica al país, aunque fiscalmente quede a "deber" al gobierno y al fisco, como consecuencia de su propia naturaleza: la informalidad.

Por último, con relación al área fiscal, la nueva disciplina en la materia es el distintivo del presente gobierno, reflejándose en las medidas para salvaguardar los ingresos, los cuales por mandato constitucional debe obtener el Estado. La praxis recaudatoria que ha caracterizado a este gobierno es determinante en la forma de percibir el ejercicio recaudatorio por parte de los mexicanos.

Es importante que todos los contribuyentes cumplan con tal obligación de forma equitativa y proporcional con base en los ingresos que se percibe. Este cambio en el ejercicio recaudatorio permitirá un mayor soporte del gobierno ante situaciones emergentes como la de la pandemia causada por el COVID-19.

No obstante, los contribuyentes deben participar de forma activa para que exista la capacidad de solventar este tipo de situaciones por parte del gobierno. Asimismo, es de interés para los contribuyentes saber qué escenario fiscal se puede prever derivado de la pandemia que el COVID-19 ha ocasionado a nivel mundial. Al respecto, diversos organismos y confederaciones empresariales se han manifestado por medio de cartas y solicitudes, para obtener algunas oportunidades y 
beneficios fiscales que permitan aminorar el impacto económico que causó el COVID-19.

Una de las primeras propuestas busca ampliar los plazos mensuales para el pago de ISR del mes de marzo y abril al 16 de mayo y junio; sin embargo, no se ha pronunciado el SAT respecto a una ampliación para el tipo de declaraciones mensuales. En cuanto a la depreciación y amortización acelerada fiscal de activos fijos adquiridos recientemente, se suma la exención del Impuesto Sobre Nómina hasta finales del año 2020, para empresas turísticas como hoteleras, transporte y aéreas, la suspensión temporalmente de los pagos mensuales de ISR.

Asimismo, importantes organizaciones empresariales, como las maquiladoras, buscan devoluciones de IVA de forma inmediata, de modo que el paquete de incentivos fiscales sea emitido buscando apoyo al empleado, empleador y a la inversión.

Por lo expuesto, el COVID-19 alteró diversos sectores económicos, mermando las contribuciones que el Estado requiere para solventar sus actividades; sin embargo, el impacto durante este año 2020 en el campo de los negocios, específicamente en el sector de las MiPYMES, es un foco que requiere de especial atención debido al papel estratégico que ocupa en la economía nacional.

Finalmente, en el marco de la pandemia, el 1 ro de abril de 2020, la SHCP entregó al Congreso de la Unión el comunicado con Pre-Criterios de 2021, con el cual prevé un fuerte impacto en la actividad económica y las finanzas públicas del año 2020 (SAT, 2020b). En este documento el Gobierno de México plasma la nueva cultura tributaria que busca implementar, siempre buscando un balance e impulso en la economía, con miras a una mayor recaudación para financiar programas y eventos que requieran de recursos, buscando la inversión y el crecimiento.

En definitiva, existen grandes retos en materia del factor humano, financiero y fiscal para el año 2021, seguramente lo que resta del sexenio se enfocará en estabilizar de nueva cuenta la economía nacional y la dinámica empresarial en todas sus escalas. Sin embargo, con este escenario, el presidente López Obrador no renuncia a la idea de continuar los grandes proyectos nacionales de infraestructura 
como el Tren Maya, el cual prevé un impacto económico favorable para el históricamente olvidado sureste mexicano; y el nuevo Aeropuerto Internacional "General Felipe Ángeles", en la base área militar de Santa Lucía, que reemplazará al tan cuestionado proyecto del Aeropuerto de Texcoco, del gobierno de su antecesor Enrique Peńa Nieto.

Los grandes proyectos de infraestructura nacional no son aislados, se encuentran enmarcados en la coyuntura de la pandemia del COVID19, así como de una inercia en materia de inseguridad a nivel nacional de sexenios anteriores creada por el gobierno de Felipe Calderón y que se agudizó con Enrique Peña Nieto, así como de intentonas de movimientos políticos de los opositores al gobierno actual, los cuales buscan ganar simpatizantes y votantes con miras a las elecciones intermedias de 2021.

El próximo ańo, sin duda, será determinante para México, por lo que el actual gobierno debe pensar en un eficaz plan de recuperación económica, sustentado en la ya referida disciplina fiscal, sin dejar de lado la materia sanitaria y de seguridad que aqueja al país. El presidente López Obrador sabe de la importancia del segundo semestre del año 2020, si no quiere llegar tan comprometido en el índice de aprobación y en materia electoral a las elecciones intermedias, en las cuales por primera vez en la historia un presidente de México se someterá a la revocación de mandato. El próximo año se sabrá si la estrategia política, económica, de seguridad, sanitaria y electoral le rendirá frutos a la izquierda mexicana.

\section{Referencias}

Aguilar, J. (2020). México: efectos del COVID-19 en el mercado del trabajo. Ciudad de México: Universidad Nacional Autónoma de México. Recuperado de https://www.iis.unam.mx/blog/ mexico-efectos-del-covid-19-en-el-mercado-del-trabajo/

Alfaro, F. (2020, 20 de abril). México, con el $82 \%$ de sus empresas cerradas o con horarios restringidos. Quadratin. Recuperado de https://www.quadratin.com.mx/principal/mexico-con-el-82de-sus-empresas-cerradas-o-con-horarios-restringidos/ 
Ayala, C. (2020, 21 de abril). Gobierno de CDMX implementa 5 nuevas medidas ante Fase 3 por la pandemia de Covid-19. El Economista. Recuperado de https://www.eleconomista.com.mx/estados/ Gobierno-de-CDMX-implementa-5-nuevas-medidas-ante-Fase3-por-la-pandemia-de-Covid-19-20200421-0129.html

Baldwin, R. E. \& Di Mauro, W. (2020). Mitigating the COVID economic crisis (No. BOOK). Centre for Economic Policy Research.

Brooks, S. K., Webster, R. K., Smith, L. E., Brooks Woodland, L., Wessely, S., Greenberg, N. \& Rubin, G. J. (2020). The psychological impact of quarantine and how to reduce it: rapid review of the evidence. The Lancet. 395, 912-20. Doi: https://doi. org/10.1016/S0140-6736 (20)30460-8

Díaz, A. (2020, 04 de junio) Desempleo, informalidad y precariedad: la pandemia de los jóvenes en tiempos de COVID-19. Nexos. Recuperado de https://economia.nexos.com.mx/?s=covid

EFE. (2020, 07 de mayo). México ha perdido ya 500 mil empleos formales por coronavirus. El Universal. Recuperado de https:// www.eluniversal.com.mx/nacion/mexico-ha-perdido-ya-500mil-empleos-formales-por-coronvirus-0

El Financiero. (2020, 24 de mayo). Se perderán 1 millón de empleos: AMLO. El Financiero. Recuperado de https://www.elfinanciero. com.mx/nacional/se-perderan-1-millon-de-empleos-por-covid19-amlo

Flores, Z. (2020, 03 de marzo). Medidas del Gobierno por COVID-19 causan confusión en empresas. El Financiero. Recuperado de https://www.elfinanciero.com.mx/economia/medidas-del-gobierno-por-covid-19-causan-confusion-en-empresas

García, A. \& González, K. (2020, 26 de marzo). Los efectos macroeconómicos del COVID-19 en México. Nexos. Recuperado de https://economia.nexos.com.mx/?p=2967

Gascón, V. (2020, 09 de abril). Resistirían pymes con más de 5 años. ElNorte. Recuperado de https://www.elnorte.com/aplicacioneslibre/preacceso/articulo/default.aspx?__rval=1\&urlredirect=https://www.elnorte.com/resistirian-pymes-con-mas-de-5-anos/ ar1915665? referer=--7d616165662f3a3a6262623b727a7a727 $9703 b 767 a 783 a--$ 
Gopinath, G. (2020). Limiting the economic fallout of the coronavirus with large targeted policies. Mitigating the COVID Economic Crisis: Act Fast and Do Whatever, 41.

Gourinchas, P. O. (2020). Flattening the pandemic and recession curves. Mitigating the COVID Economic Crisis: Act Fast and Do Whatever, 31.

Guardado, S. C. (2018). Neuropsicología: su importancia en el comportamiento del trabajador. Iberoamerican Business Journal, 1(2), 43-59. Doi: https://doi.org/10.22451/5817.ibj2018. vol1.2.11010

Guardado, S. C. (2020). Neuropsicología Organizacional y su Influencia en el Proceso Decisorio del Trabajador. Gente Clave, 4(1), 8-29. Recuperado de http://revistas.ulatina.edu.pa/index. $\mathrm{php} /$ genteclave/article/view/120

Guardado, S. C. (2019). Neuropsicología Organizacional: Nueva perspectiva en la Gestión del Talento Humano. Ciencia, Economia y Negocios. 3(1) 49-57. DOI: 10.22206/CEYN.2019. V3I1.PP49-57

Hallazgos México. (2020). CFO Pulse: Impactos financieros del COVID-19 en las empresas. Recuperado de https://www.pwc. $\mathrm{com} / \mathrm{mx} / \mathrm{es} /$ gestion-de-crisis/covid-19/cfo-pulse-survey.html

Hernández, L. (2020, 27 de marzo) Prevé la OCDE fuerte impacto económico para México por COVID-19. El Financiero. Recuperado de https://www.elfinanciero.com.mx/economia/ cada-mes-de-paro-en-la-produccion-le-costara-2-puntos-delpib-a-principales-economias-ocde

Instituto Nacional de Estadística, Geografía e Informática. (2019a). INEGI Presenta resultados de la encuesta nacional sobre productividad y competitividad de las micro, pequeñas y medianas empresas (ENAPROCE) 2018. Ciudad de México: Secretaría de Economía.

Instituto Nacional de Estadística, Geografía e Informática. (2019b). Censos Económicos 2019. Recuperado de https://www.inegi.org. $\mathrm{mx} /$ programas/ce/2019/

Ioannidis, J. P. (2020). A fiasco in the making? As the coronavirus pandemic takes hold, we are making decisions without reliable data. Stat, 17. 
Marco, M. (2020, 24 de abril). Han cerrado 270 mil empresas capitalinas debido al coronavirus: Canaco CDMX. Recuperado de https://marcomares.com.mx/capital/han-cerrado-270-mil-empresas-capitalinas-debido-al-coronavirus-canaco-cdmx/

México. (2017). Constitución Política de los Estados Unidos Mexicanos.

Morales, R. (2020, 11 de mayo). Permanecen cerradas $45 \%$ de las empresas maquiladoras y manufactureras en México. El Economista. Recuperado de https://www.eleconomista.com.mx/ empresas/Permanecen-cerradas-45-de-las-empresas-maquiladoras-y-manufactureras-en-Mexico-20200511-0056.html

Organización Mundial de la Salud. (2016). Protección de la Salud Mental y Atención Psicosocial en Situaciones de Epidemias. Washington D. C.: OMS-OPS. Disponible en https://www. paho.org/disasters/index.php?option=com_docman\&view=download\&category_slug=informes-tecnicos\&alias=2539-proteccion-salud-mental-atencionpsicosocial-situaciones-epidemias-2016-539\&Itemid $=1$ 179\&lang $=$ en

Reforma (2020, 09 de abril). Peligran 1.8 millones de pymes. Diario de Chihuahua. Recuperado de https://www.eldiariodechihuahua.mx/economia/peligran-18-millones-depymes-20200409-1649926.html

Rogers, C. (2012). Grupos de encuentro. (2a ed.) Buenos Aires: Amorrortu Edrs.

Secretaría de Economía. (2020). Créditos para estimular y reactivar la economía. Ciudad de México: Gobierno de México. Recuperado de https://www.gob.mx/se/acciones-y-programas/creditos-para-estimular-y-reactivar-la-economia?state=published

Secretaría de Salud. (2020). Lineamientos de respuesta y de acción en salud mental y adicciones para el apoyo psicosocial durante la pandemia por COVID-19 en México. Ciudad de México: Gobierno de México.

Secretaría del Trabajo y Previsión Social. (2020a, 19 de mayo). Comunicado Número 018/2020. Ciudad de México: Gobierno de México.

Secretaría del Trabajo y Previsión Social. (2020b). Guía de acción para los centros de trabajo ante el Covid-19. Ciudad de México: Gobierno de México. 
Secretaría del Trabajo y Previsión Social. (2020c). En marzo se perdieron más de 130 mil empleos formales ante los efectos del COVID-19. Ciudad de México: Gobierno de México.

Secretaría del Trabajo y Previsión Social. (2019). Encuesta Nacional de Ocupación y Empleo. Ciudad de México: Gobierno de México.

Servicio de Administración Tributaria. (2020a, 07 de abril). Incrementa recaudación por ingresos tributarios en el primer trimestre 2020. Recuperado de https://www.gob.mx/sat/prensa/incrementa-recaudacion-por-ingresos-tributarios-en-el-primer-trimestre-de-2020-10-2020

Servicio de Administración Tributaria. (2020b, 01 de abril). Comunicado No. 034 Ejecutivo Federal, por conducto de la SHCP, entrega al H. Congreso de la Unión el documento de "Pre-Criterios 2021". Recuperado de https://www.gob.mx/shcp/prensa/comunicadono-034-ejecutivo-federal-por-conducto-de-la-shcp-entrega-alh-congreso-de-la-union-el-documento-de-pre-criterios-2021

Verity, R., Okell, L. C., Dorigatti, I., Winskill, P., Whittaker, C., Imai, N. \& Dighe, A. (2020). Estimates of the severity of coronavirus disease 2019: a model-based analysis. The Lancet infectious diseases, 20(6): 669-677.

Weiland, D. \& Kynge J. (2020, 20 de marzo). China carece del 'apetito' para salvar la economía mundial. El Economista. Recuperado de https://www.elfinanciero.com.mx/financial-times/ china-carece-del-apetito-para-salvar-la-economia-mundial 